\title{
Wandering Neuronal Migration in the Postnatal Vertebrate Forebrain
}

\author{
Benjamin B. Scott, ${ }^{1}$ Timothy Gardner, ${ }^{2} \mathrm{Ni}$ Ji, ${ }^{1}$ Michale S. Fee, ${ }^{2}$ and Carlos Lois ${ }^{3}$ \\ ${ }^{1}$ Department of Brain and Cognitive Sciences and ${ }^{2} \mathrm{McGovern}$ Institute for Brain Research, Department of Brain and Cognitive Sciences, Massachusetts \\ Institute of Technology, Cambridge, Massachusetts 02139, and ${ }^{3}$ Department of Neurobiology, University of Massachusetts Medical School, Worcester, \\ Massachusetts 01655
}

\begin{abstract}
Most non-mammalian vertebrate species add new neurons to existing brain circuits throughout life, a process thought to be essential for tissue maintenance, repair, and learning. How these new neurons migrate through the mature brain and which cues trigger their integration within a functioning circuit is not known. To address these questions, we used two-photon microscopy to image the addition of genetically labeled newly generated neurons into the brain of juvenile zebra finches. Time-lapse in vivo imaging revealed that the majority of migratory new neurons exhibited a multipolar morphology and moved in a nonlinear manner for hundreds of micrometers. Young neurons did not use radial glia or blood vessels as a migratory scaffold; instead, cells extended several motile processes in different directions and moved by somal translocation along an existing process. Neurons were observed migrating for $\sim 2$ weeks after labeling injection. New neurons were observed to integrate in close proximity to the soma of mature neurons, a behavior that may explain the emergence of clusters of neuronal cell bodies in the adult songbird brain. These results provide direct, in vivo evidence for a wandering form of neuronal migration involved in the addition of new neurons in the postnatal brain.
\end{abstract}

\section{Introduction}

The migration and integration of new neurons into brain circuits is an essential process in vertebrate development. In mammals, this process is completed before or soon after birth, except in the dentate gyrus of the hippocampus (Altman and Das, 1965; van Praag et al., 2002) and the olfactory bulb (Altman, 1969; Lois and Alvarez-Buylla, 1994) in which it continues throughout life. In contrast, postnatal neurogenesis is found throughout the forebrain of many other vertebrate species (Kaslin et al., 2008). Since its discovery, postnatal neurogenesis has stimulated interest as a potential therapeutic treatment (Nottebohm, 1985; Okano and Sawamoto, 2008) and as a substrate for behavioral plasticity (Alvarez-Buylla et al., 1990a).

Songbirds are a useful model system for the study of postnatal neurogenesis because they add new neurons to many regions of the forebrain, including the HVC (high vocal center), a specialized forebrain circuit that controls singing (Paton and Nottebohm, 1984). HVC continually receives new excitatory neurons that project to downstream motor nuclei forming a pathway essential for singing (Alvarez-Buylla et al., 1988a). The addition of new neurons to HVC is increased by both the death of mature

Received April 29, 2011; revised Nov. 8, 2011; accepted Nov. 19, 2011

Author contributions: B.B.S., T.G., and C.L. designed research; B.B.S., T.G., N.J., and C.L. performed research; B.B.S., T.G., M.S.F., and C.L. contributed unpublished reagents/analytic tools; B.B.S., T.G., and C.L. analyzed data; B.B.S. and C.L. wrote the paper.

This work was supported by a grant from the Ellison Foundation (C.L.). We thank S. Turaga and A. Andalman for help with data analysis and T. Davidson and N. Denisenko for their comments on this manuscript.

Correspondence should be addressed to Carlos Lois, Department of Neurobiology, Lazare Research Building, 364 Plantation Street, Worcester, MA 01655. E-mail: Carlos.Lois@umassmed.edu.

DOI:10.1523/JNEUROSCI.2145-11.2012

Copyright $\odot 2012$ the authors $\quad 0270-6474 / 12 / 321436-11 \$ 15.00 / 0$ neurons (Scharff et al., 2000) and by behavioral demands, such as song learning (Nordeen and Nordeen, 1988; Kirn et al., 1994) and high rates of singing (Alvarez-Borda and Nottebohm, 2002). New neurons are born in the walls of the lateral ventricle (AlvarezBuylla et al., 1990b; Scott and Lois, 2007) and migrate for 1-2 weeks before they reach their final location (Alvarez-Buylla et al., 1988b). However, little is known about how these new neurons move through the mature nervous system and integrate into existing circuits.

It has been proposed that fibers of radial glia provide a migratory scaffold for young neurons and guide them to their integration targets in the zebra finch brain (Alvarez-Buylla et al., 1988b). This form of migration, termed radial migration, is the primary form of migration for projection neurons in the embryonic cortex (Ayala et al., 2007). However, as development proceeds, the amount of extracellular space decreases (Bondareff and Narotzky, 1972) and the stability of the neuropil increases (Holtmaat et al., 2005), raising the possibility that another specialized form of migration may be required to navigate the postnatal brain. Indeed, in the mature mammalian brain, newborn olfactory granule neurons migrate along a specialized corridor called the rostral migratory stream (Lois et al., 1996). We wondered whether a specialized form of migration also exists for new neurons in the songbird brain.

To address this question, we used two-photon in vivo imaging to observe the migration and integration of genetically labeled new neurons into the HVC of juvenile zebra finches. We observed that most young neurons exhibit a multipolar morphology, extend dynamic processes that explore extracellular space, and migrate in a wandering manner. After $\sim 2$ weeks, cells stop migration in close proximity to resident neu- 
rons and begin to integrate into the circuit. These data reveal a novel form of neuron migration related to the addition of new neurons to the juvenile songbird brain.

\section{Materials and Methods}

Virus production. All oncoretroviral vectors used were based on the Moloney murine leukemia virus. Gene expression was driven by the internal promoter of the Rous sarcoma virus, which we have shown previously to be a strong promoter in migrating neurons in the zebra finch (Scott and Lois, 2007). Viral particles were produced as described previously (Lois et al., 2002) and concentrated to $0.5-5 \times 10^{6}$ infectious units per microliter. Aliquots of viral vector were stored at $-80^{\circ} \mathrm{C}$ until used.

Animals. All experiments were performed in accordance with protocols approved by the Committee on Animal Care at the Massachusetts Institute of Technology. Data were obtained from juvenile zebra finch males (44-72 d old) from our breeding colony at the Massachusetts Institute of Technology.

Surgical procedure. At 38-55 d old, birds were removed from the breeding colony and underwent stereotaxic surgery. Anesthesia was maintained with 1-2\% isoflurane in air. Birds for immunohistochemical analysis received $2-\mathrm{mm}$-diameter craniotomies dorsal to HVC on the right hemisphere. Injections of GFP-carrying viral vector (600-900 nl total volume) were targeted to the ventricular zone (VZ) dorsal to HVC $(0.0 \mathrm{~mm}$ anterior, $2.1 \mathrm{~mm}$ lateral of the bifurcation of the sagittal sinus, and $0.1-0.2 \mathrm{~mm}$ below the dura). After recovery, finches were housed with other males in our aviary.

Surgery to prepare animals for in vivo imaging was the same as above except for the following modifications. One molar mannitol $(20 \mu \mathrm{l} / \mathrm{g})$ was administered to decrease intracranial pressure and reduce bleeding during surgery. Larger craniotomies, 3-4 $\mathrm{mm}$ in diameter, were made above HVC to accommodate the chronic implant. Care was taken to minimize bleeding of the dura surface. After skull removal and viral injections, a thin layer of transparent biocompatible silicone (Kwik-Sil; WPI) was applied to the dura, and a coverglass was placed on top. We began experiments with 5-mm-diameter coverglass (1943-00005; Bellco Glass) and switched to 3-mm-diameter coverglass (3 mm circular, \#0, Corning 0211 borosilicate glass; Thermo Fisher Scientific). We noticed no difference in the clarity of the optical implant or health of the animal between glass types but found surgery more successful with smaller craniotomies. Optical-curing dental cement (Pentron Clinical Technologies) was used to affix the coverglass to the skull. A small steel plate $(4.75 \times 2.25 \times 1.00 \mathrm{~mm})$ with threaded screw holes was embedded in the dental cement, allowing the head to be temporarily mounted onto the microscope stage to maintain head placement during imaging. Birds also received $50 \mathrm{nl}$ injections of DiI (Invitrogen) dissolved to $5 \mathrm{mg} / \mathrm{ml}$ in dimethylformamide (Sigma) into area X (5.2 $\mathrm{mm}$ anterior, $14 . \mathrm{mm}$ lateral of the bifurcation of the sagittal sinus, and $2.75 \mathrm{~mm}$ below the dura). After surgery and between imaging sessions, a small amount of opaque biocompatible silicone (Kwik-Cast; WPI) was applied to the coverglass to protect the glass from debris and the brain from light. Birds were housed individually in acoustically isolated chambers. Songs were recorded in some birds to verify that the optical window, surgery, and repeated anesthesia did not disrupt normal development. Birds were kept on $12 \mathrm{~h}$ or $16 / 8 \mathrm{~h}$ light/dark schedules.

Histology and immunocytochemistry. Histological procedures are similar to those described previously (Scott and Lois, 2007). Eight days after injection with retroviral vectors, animals were deeply anesthetized and perfused with $3 \%$ paraformaldehyde (Sigma). After removal from the skull, brains were postfixed in $3 \%$ paraformaldehyde overnight at $4^{\circ} \mathrm{C}$. Tissue sections, $40 \mu \mathrm{m}$, were cut with a vibrating microtome (Leica). Sections containing HVC were incubated in blocking solution with $2 \%$ milk and $0.25 \%$ Triton X-100 in PBS for 20 min at room temperature and then transferred to primary antibody solution that included rabbit antiGFP (AB3080; Millipore Bioscience Research Reagents) diluted 1:400 in blocking solution and a second primary antibody (see below for list of antibodies and dilutions) in blocking solution and incubated overnight at $4^{\circ} \mathrm{C}$. Sections were washed three times in PBS for $45 \mathrm{~min}$ total and then transferred to secondary antibody solution of Alexa Fluor 488 goat antirabbit IgG (A11008; Invitrogen) and Alexa Fluor 555 donkey anti-goat IgG (A21432; Invitrogen) or Alexa Fluor 647 goat anti-mouse IgM (A21238; Invitrogen), each diluted 1:750 in blocking solution, incubated $2 \mathrm{~h}$ at room temperature, washed as before, and mounted. Imaging was performed with an Olympus Fluoview confocal microscope and analyzed with NIH ImageJ.

To examine the relationship between neuroblasts and radial glia, sections were stained for vimentin using 40E-C supernatant (Developmental Studies Hybridoma Bank, University of Iowa) diluted 1:10. Doublecortin (DCX) was detected using a goat polyclonal antibody (diluted in blocking solution 1:500) (sc8066; Santa Cruz Biotechnology). Hu was detected using a mouse monoclonal antibody (diluted in blocking solution 1:25) (A21271; Invitrogen). NeuN was detected using a mouse monoclonal antibody (diluted in blocking solution 1:500) (MAB377; Millipore Bioscience Research Reagents).

To estimate the percentage of $\mathrm{HVC}_{\mathrm{X}}$ neurons labeled by our injection of DiI into area X, we performed dual injections of two different color fluorescent retrograde tracers. In three adult male zebra finches, we injected $60 \mathrm{nl}$ of DiI into the right area X, and then we injected $60 \mathrm{nl}$ of the $\beta$-subunit of cholera toxin conjugated to Alexa Fluor 488 (CTB-488) at a location $200 \mu \mathrm{m}$ away from the site of the DiI injection. After 1 week, we perfused the animals and counted the number of cells in HVC labeled with DiI and/or CTB-488 in histological sections. We compared the percentage of DiI-labeled cells and CTB-488-labeled cells to all labeled $\mathrm{HVC}_{\mathrm{X}}$ (250 cells total: DiI alone, CTB-488 alone, and dual labeled cells). DiI labeled $99.0 \pm 1.0 \%$ of all labeled $\mathrm{HVC}_{\mathrm{X}}$ neurons, whereas CTB-488 labeled $97.3 \pm 1.7 \%$ of all labeled $\mathrm{HVC}_{\mathrm{X}}$. This observation suggests that a $60 \mathrm{nl}$ injection of DiI into the center of area $\mathrm{X}$ is sufficient to label the majority of $\mathrm{HVC}_{\mathrm{X}}$ neurons. This observation also supports previous reports that the projection from $\mathrm{HVC}$ to area $\mathrm{X}$ is not topographic (Luo et al., 2001).

Two-photon microscope. Imaging was performed on a custom-built two-photon laser-scanning microscope. GFP-positive $\left(\mathrm{GFP}^{+}\right)$and $\mathrm{DiI}^{+}$cells were excited by near-infrared light $(960 \mathrm{~nm})$ produced by a titanium:sapphire laser (Tsunami; Spectra Physics) pumped by a 10 -W solid-state laser. Images were acquired using a $20 \times, 0.95 \mathrm{NA}$ water-immersion objective lens (Olympus) and photomultiplier tubes (H7422; Hamamatsu).

Time-lapse imaging. Beginning 4-7 d after surgery, animals were anesthetized with $0.8-1.2 \%$ isoflurane in oxygen, and their head was fixed under the two-photon microscope objective. The birds rested on a pad heated to $42^{\circ} \mathrm{C}$. The microscope objective and head post were also heated to $42^{\circ} \mathrm{C}$, and the immersion fluid above the objective was heated to $34-36^{\circ} \mathrm{C}$. To produce high time-resolution movies of migration, images were acquired every $6 \mathrm{~min}$ for up to $7 \mathrm{~h}$ ( $n=3$ birds). Imaging was performed during night hours, which allowed us to use lower concentrations of isoflurane $(\sim 0.8 \%)$ to maintain anesthesia. Other birds were imaged every $48 \mathrm{~h}$ (11 birds), $12 \mathrm{~h}$ ( 2 birds), and $3 \mathrm{~h}$ ( 2 birds). The duration of imaging sessions ranged from 30 to $45 \mathrm{~min}$. Between imaging sessions, animals were housed singly or in pairs.

Labeling blood vessels. To test whether blood vessels formed a scaffold for migration in HVC, we recorded the positions of $11 \mathrm{GFP}^{+}$cells from two animals at $3 \mathrm{~h}$ intervals for up to 15 or $18 \mathrm{~h}$. Each imaging session lasted 20-30 min. This time included the induction of anesthesia, mounting of the finch in the head-restraint apparatus, and the acquisition of the $z$-stack through HVC. After imaging, animals were returned to their cage until the next session. To label blood vessels, we injected $50 \mu \mathrm{l}$ of $20 \mathrm{~mm}$ sulforhodamine 101 (Invitrogen) into the breast muscle 5-10 min before the final imaging session. This protocol yielded identical results compared with intramuscular injection of fluorescein conjugated to 70,000 molecular weight dextran (Invitrogen) and labeled blood vessels for many $(12+)$ hours. We then compared the blood vessel pattern with the migration trajectories of the $\mathrm{GFP}^{+}$cells and recorded the position of the soma to the nearest blood vessel.

Data analysis and statistics of two-photon microscopy images. Images were acquired using ScanImage software (Pologruto et al., 2003) and processed for contrast, color, and alignment using NIH ImageJ. Z-stacks from individual time points were aligned using the Stacks-shuffling/ 
Align Slices plug-in available from the Wright Cell Imaging Facility. GFP ${ }^{+}$cells were traced using Neurolucida. To track migration paths, image stacks acquired at different time points were first aligned in $3 \mathrm{D}$ using the position of the center of the cell body of DiI-labeled $\mathrm{HVC}_{\mathrm{X}}$ neurons as reference points. The position of the center of $\mathrm{GFP}^{+}$cells was identified by hand and recorded in NIH ImageJ. Migration trajectories were reconstructed using MATLAB.

After processing, we took two measurements of cell movement using the reconstructed trajectories. The first was path length (i.e., total distance we observed the cell to move) and the second was displacement (i.e., radial distance, the distance between the start and end points along a path). In addition, we also calculated displacement for subsets of the migration path corresponding to discrete time intervals (i.e., cell displacement over $3 \mathrm{~h}$ ), which we used to compare migration across different imaging timescales. The Rayleigh's test, a statistical measure of uniformity in circular data (Fisher, 1996), was performed in MATLAB using a script written by Philip Berens (Max Planck Institute for Biological Cybernetics), which is available at http://www. mathworks.com/matlabcentral/fileexchange/ 10676.

To evaluate the significance of the difference in the $r^{2}$ statistic between the linear model and the random walk model, we calculated the $p$ value using a bootstrapping approach. We created a surrogate dataset, composed of elements from our original dataset, of 641 time points from 24 neurons but drawn at random with replacement. We then performed regression analysis on the surrogate dataset assuming a linear model (displacement vs time) and a random walk model (displacement vs the square root of time). This procedure was iterated 1000 times, and, for each iteration, we determined whether the $r^{2}$ value was higher for the linear model or the random walk model. The $p$ value we report is the ratio of the number of iterations in which the $r^{2}$ value for the regression to the linear model was greater than the $r^{2}$ value for the regression to the random walk model versus the total iterations. The $r^{2}$ value for the linear model was less than the $r^{2}$ value for the random walk model in all iterations, suggesting a $p<0.001$.

To quantify the proportion of tips that contained swellings, we examined 71 unique processes from more than four cells imaged at 6 min intervals. Process tips were considered growing if they experienced at least $18-30 \mathrm{~min}$ of growth. Process tips were considered retracting if they experienced at least $18-30 \mathrm{~min}$ of retraction. Some processes experienced periods of both growth and retraction over the duration of imaging $(5.5 \mathrm{~h})$. For these processes, we counted each period of growth or retraction as a unique process.

\section{Results}

Multiple migratory neuronal types in the postnatal brain HVC contains two types of projection neurons, those neurons projecting to area $\mathrm{X}$ of the striatum and those that project to the premotor nucleus RA, henceforth referred to as $\mathrm{HVC}_{\mathrm{X}}$ and
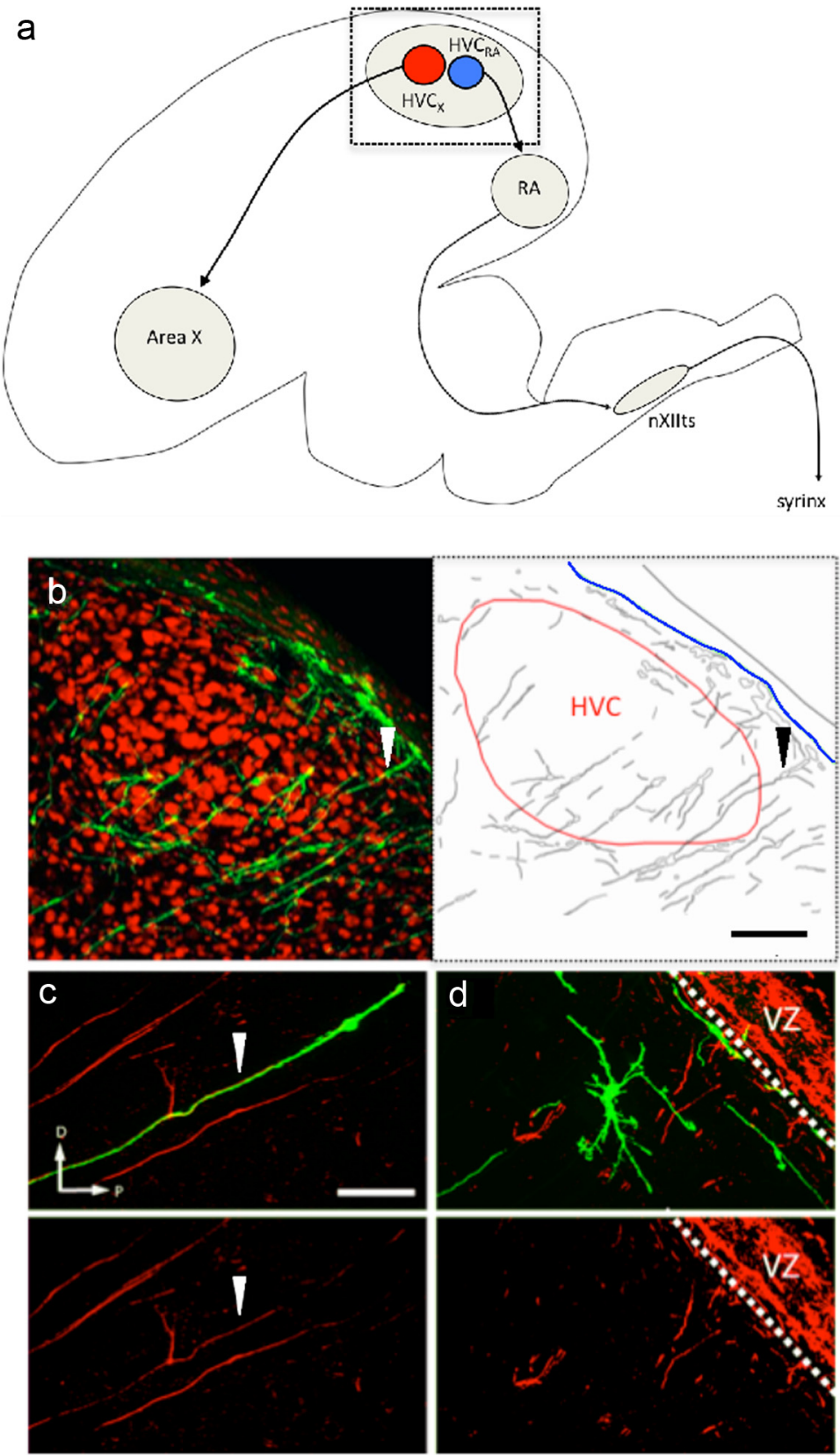

Figure 1. Bipolar and multipolar cells were observed in HVC $8 \mathrm{~d}$ after injections of an oncoretroviral vector into the VZ. $\boldsymbol{a}$, Schematic of the major pathways ( $\mathrm{HV}_{\mathrm{RA}}$, blue circle; $H V C_{X}$, red circle) within the zebra finch song system. New $\mathrm{HVC}_{\mathrm{RA}}$ neurons are born postnatally and added to HVC throughout life. Dotted box indicates the region shown in $\boldsymbol{b}$. $\boldsymbol{b}$, Left, Confocal image of GFP ${ }^{+}$ newborn neurons (green) and NeuN ${ }^{+}$mature resident neurons (red) at 8 dpi in HVC. Right, Tracing of the confocal image, revealing the relative position of GFP ${ }^{+}$cells (traces in gray), HVC, and the VZ (blue line). GFP ${ }^{+}$cells were found within HVC (red line indicates HVC borders), outside HVC, and adjacent to the VZ. Arrowhead indicates a bipolar cell that extended a leading processes through HVC into surrounding brain regions. Scale bar, $200 \mu \mathrm{m}$. c, Top, Confocal image of a bipolar cell (green, arrowhead) within HVC associated with a vimentin ${ }^{+}$radial fiber (red). Scale bar, $50 \mu$ m.d, Image of a multipolar cell (green) in HVC, not associated with radial fibers (red). Vimentin ${ }^{+}$fibers (red) were enriched within the VZ (dashed line indicates ventral border of the VZ). D, Dorsal; P, posterior. In c, and $\boldsymbol{d}$, top panels show merged green (showing GFP ${ }^{+}$cells) and red (showing immunostaining with vimentin antibodies) channels, and bottom panels show red channel alone.

$\mathrm{HVC}_{\mathrm{RA}}$ neurons, respectively (Fig. 1a). $\mathrm{HVC}_{\mathrm{X}}$ neurons are born almost exclusively during embryonic development and many persist for the lifetime of the animal (Alvarez-Buylla et al., 1988a), whereas most $\mathrm{HVC}_{\mathrm{RA}}$ neurons are born postnatally and continue to be added throughout adult life (Kirn et al., 1999). We previously determined that $\mathrm{HVC}_{\mathrm{RA}}$ neurons, which are born during the critical period for vocal learning in zebra finches $(40-90 \mathrm{~d}$ 

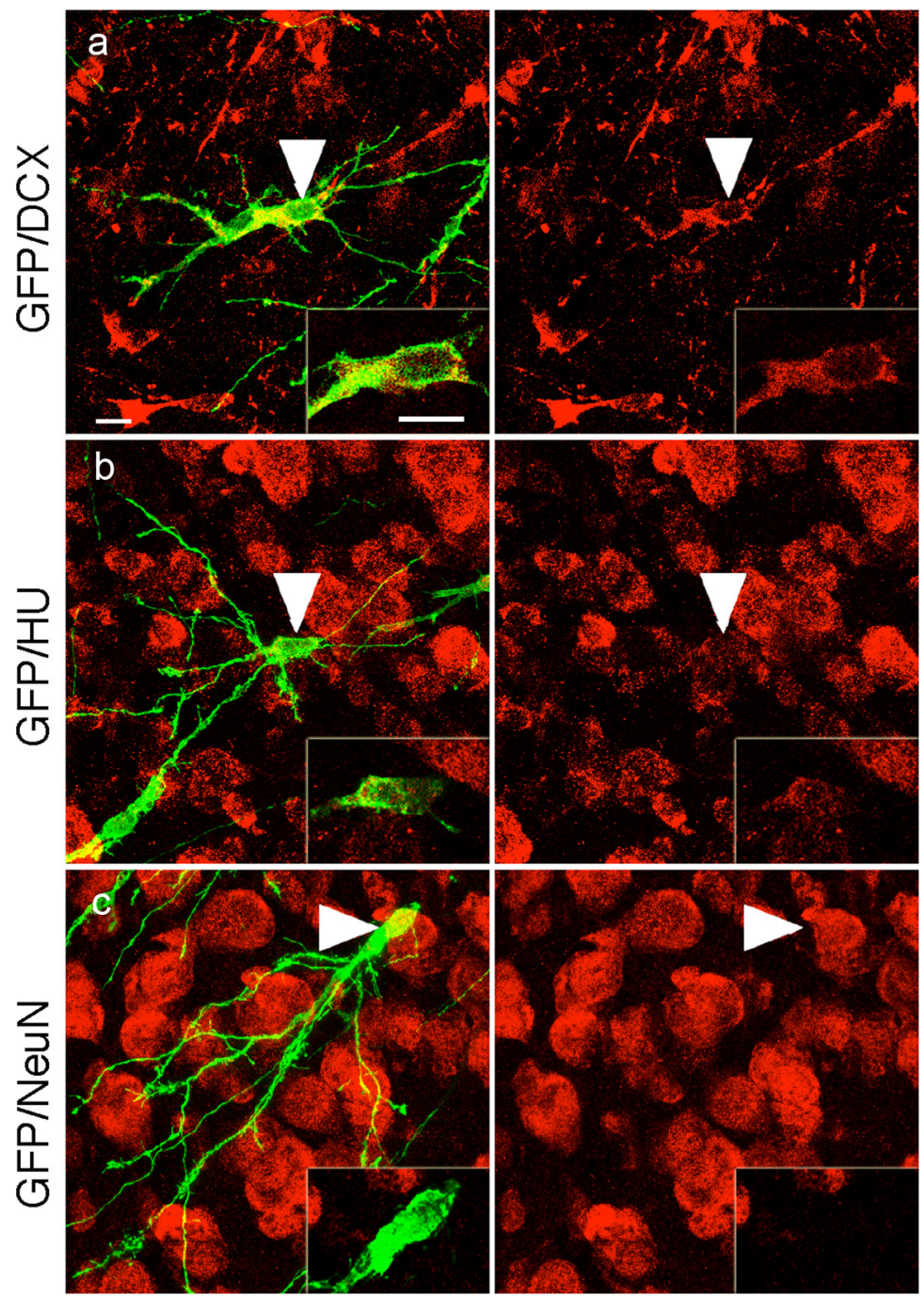

Figure 2. Multipolar cells in HVC express markers for migratory neurons. Confocal microscopy images of GFP-expressing new neurons in histological sections $8 \mathrm{~d}$ after oncoretroviral injection. Left panels show a merged image between GFP (green) and the fluorescent antibody stain against protein markers for DCX $(\boldsymbol{a}), \mathrm{Hu}(\boldsymbol{b})$, and NeuN (c) (red). Right panels show the staining for the neuronal markers only. Arrowheads indicate the position of the GFP ${ }^{+}$cell body. Inset in the bottom right corner shows a highmagnification image of the cell body. Cells were strongly positive for DCX and weakly positive for Hu. Colabeling between GFP and NeuN was rarely observed at $8 \mathrm{dpi}$. Scale bar, $10 \mu \mathrm{m}$.

Table 1. Cells obtained for the different in vivo imaging intervals

\begin{tabular}{lccc}
\hline Imaging interval (h) & Number of cells & Duration (h) & Number of animals \\
\hline 0.1 & 12 & $5.3 \pm 1.1$ & 3 \\
3 & 11 & $13.5 \pm 1.7$ & 2 \\
12 & 3 & $92.0 \pm 25.0$ & 2 \\
48 & 66 & $242.4 \pm 136.8$ & 11 \\
Total & 92 & & 18 \\
\hline
\end{tabular}

after hatching), are derived from the pallial VZ dorsal to HVC (Scott and Lois, 2007). Neurons born in this region migrate to targets within $\mathrm{HVC}$ and to surrounding regions up to $3 \mathrm{~mm}$ away from the VZ. To visualize the addition of new HVC neurons, we labeled the dividing neuroblasts in this region in 40- to 60-d-old zebra finch males with a GFP-encoding oncoretroviral vector. Oncoretroviral vectors can only infect actively dividing cells, such as neuronal progenitors, and will not infect postmitotic cells, such as neurons (Roe et al., 1993). At 8 d post infection (dpi), soon after new neurons begin to enter HVC (Barami et al., 1995; Kirn et al., 1999), we examined the morphology and distribution of $\mathrm{GFP}^{+}$cells in histological sections from six birds. At 8 dpi, we observed many $\mathrm{GFP}^{+}$cells, in and around HVC as well as in the VZ (Fig. 1b). Approximately 30\% (14 of 52 ) of $\mathrm{GFP}^{+}$cells in HVC had a morphology that resembled classically described bipolar migratory neurons (Rakic, 1972) and were frequently (10 of 14) associated with radial glia (Fig. 1c). In contrast, the majority of $\mathrm{GFP}^{+}$cells in $\mathrm{HVC}$ (38 of 52) at 8 dpi had a multipolar morphology with three to eight (mean of 4.0) processes extending in multiple directions from the cell body (Fig. 1d) and were infrequently (3 of 38) associated with radial glia. Both cell types were also observed in the regions surrounding HVC. In addition, some bipolar cells within HVC extended leading processes outside HVC, suggesting that some migratory cells may pass through $\mathrm{HVC}$ en route to other areas (Fig. 1b).

To investigate the identity of multipolar cells $(n=225)$, we used antibodies against neuronal markers (Fig. 2). At 8 dpi, most multipolar cells within HVC expressed DCX (50 of 75; Fig. 2a) (a marker for migratory and immature, postmigratory neurons) (Francis et al., 1999; Gleeson et al., 1999; Boseret et al., 2007) and $\mathrm{Hu}$ (70 of 75; Fig. 2b) (a marker for neurons at all developmental stages) (Barami et al., 1995), but few expressed NeuN (1 of 75; Fig. 2 ) (a marker for mature neurons) (Mullen et al., 1992), suggesting that multipolar cells were committed to a neuronal fate although they had not completed their maturation.

\section{Migratory behavior of new neurons in vivo}

To examine the behavior of multipolar cells in vivo, we performed two-photon time-lapse imaging on $\mathrm{GFP}^{+}$cells in HVC from 4 to 22 dpi. Because HVC is a superficial brain structure extending from 100 to $700 \mu \mathrm{m}$ below the pial surface, it was possible to image $\mathrm{GFP}^{+}$ cells in vivo for up to 3 weeks. Because of the fact that we could only image a portion of HVC, it was often not possible to image the entire migratory trajectory of a single cell over multiple weeks (see Materials and Methods). Therefore, we followed GFP ${ }^{+}$cells $(n=92)$ for different durations, at $6 \mathrm{~min}, 3 \mathrm{~h}, 12 \mathrm{~h}$, or $48 \mathrm{~h}$ intervals (Table 1). To accurately identify the positions of GFP ${ }^{+}$ cells across successive imaging sessions, we retrogradely labeled $\mathrm{HVC}_{\mathrm{X}}$ neurons by injecting the fluorescent marker DiI into area $\mathrm{X}$ (Fig. 3a; see Materials and Methods). The positions of DiIlabeled $\mathrm{HVC}_{\mathrm{X}}$ neurons relative to each other did not change over time and were used to register imaging fields across successive imaging sessions (see Materials and Methods).

We first examined the behavior of $\mathrm{GFP}^{+}$cells $(n=14)$ at 3 or $12 \mathrm{~h}$ intervals over $1-6 \mathrm{~d}$. The majority of $\mathrm{GFP}^{+}$cells (13 of 14) lacked obvious polarity and had multiple processes extending in different directions, closely resembling the multipolar $\mathrm{GFP}^{+}$cells 

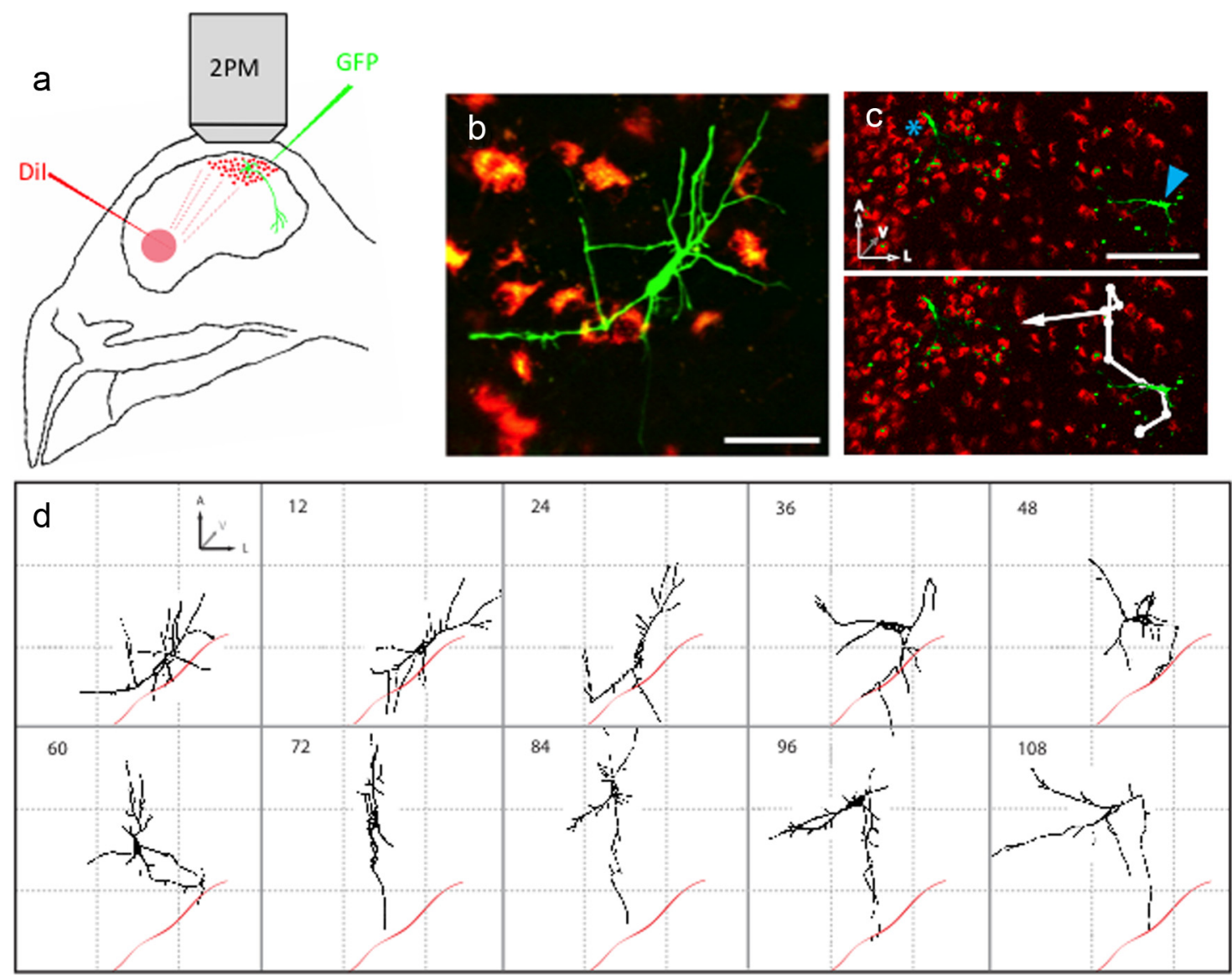

Figure 3. Two-photon in vivo imaging reveals migration of cells with multipolar morphology. $\boldsymbol{a}$, Schematic of the experimental setup for in vivo time-lapse imaging. New neurons were labeled by injecting an oncoretroviral vector carrying GFP into the VZ adjacent to HVC. Mature HVC ${ }_{X}$ neurons (red dots) were retrogradely labeled with Dil injections into area X (red circle). We imaged HVC, from 4 to 22 dpi, with a two-photon microscope (2PM). Field of view was $\sim 700 \times 1000 \times 200 \mu \mathrm{m}$ (depth). $\boldsymbol{b}$, Example of a maximum intensity projection of a multipolar GFP ${ }^{+}$cell (green) within HVC imaged in vivo at $7 \mathrm{dpi}$ using two-photon microscopy. HVC somata are labeled with Dil (red). Scale bar, $50 \mu \mathrm{m}$. c, Maximum intensity projection of two GFP ${ }^{+}$multipolar cells (labeled in green and marked by a blue asterisk and a blue arrowhead) and Dil ${ }^{+}$somata of $\mathrm{HVC}_{x}$ neurons (red) at $8 \mathrm{dpi}$. Arrowhead indicates the same multipolar cell shown in $\boldsymbol{b}$. Top shows the relative position of the two $\mathrm{GFP}^{+}$cells. Scale bar, $100 \mu \mathrm{m}$. Bottom shows a reconstruction of the migratory trajectory of the multipolar cell in $\boldsymbol{b}$ (marked with a blue arrowhead) over $120 \mathrm{~h}$ (white line); white circles indicate the position of the cell body of the migrating cell recorded at $12 \mathrm{~h}$ intervals. Note that the cell moved a short distance over the first $12 \mathrm{~h}$ of its recorded trajectory; thus, the white circles for the first and second time points are partially overlapping. $\boldsymbol{d}$, Reconstructed morphology for the multipolar cell shown in $\boldsymbol{b}$ and $\boldsymbol{c}$ at $12 \mathrm{~h}$ intervals. Time in hours is indicated in the top left corner. Red line indicates approximate location of the border of HVC. Grid spacing is $80 \mu \mathrm{m}$. A, Anterior; L, lateral; V, ventral.

observed in fixed tissue sections (Fig. $3 b$ ). The remaining cell had a bipolar morphology that, as expected, migrated in a straight line away from the lateral ventricle. Surprisingly, multipolar cells were also migratory, moving as much as $126 \mu \mathrm{m}$ in a single $12 \mathrm{~h}$ period (mean $\pm \mathrm{SD}, 42.6 \pm 27.1 \mu \mathrm{m}$ ). These cells appeared to migrate for multiple days. The longest trajectory we were able to observe before the multipolar cell left the field of view was 350 $\mu \mathrm{m}$ long and took $120 \mathrm{~h}$ (Fig. $3 c$ ). Two features of the migratory behavior of these cells were surprising and deviated from previously described forms of migration. First, multipolar cells did not migrate along straight paths; instead, they frequently changed directions and appeared to take a meandering course through HVC. As a result, the tortuosity $(\tau)$ of their trajectories, defined as the ratio between path length and the distance between the start and end points of the path, was high $(\tau=1.69 \pm 0.81)$. Second, cells changed morphology significantly between imaging sessions, adding and removing most of their processes (Fig. $3 d$ ).

The tortuous paths of multipolar cells could be indicative of migration along blood vessels, which serve as a scaffold for migrating neurons in other regions of the brain (Bovetti et al., 2007). We therefore compared the migration paths of 11 multipolar
$\mathrm{GFP}^{+}$cells with the pattern of blood vessels (Fig. 4; see Materials and Methods). None (0 of 11) of the multipolar cells followed the pattern of blood vessels, suggesting that these newly generated cells did not use blood vessels as a scaffold for their migration.

\section{Migration dynamics of multipolar cells}

To investigate migratory mechanisms, we acquired time-lapse images of 12 additional $\mathrm{GFP}^{+}$cells in HVC every 6 min for 3.5-7 h (Movie 1). For both bipolar $(n=1)$ and multipolar $(n=11)$ cells, movement of the cell body occurred by translocation of the nucleus along one of the processes emanating from the cell body ( 24 of 24 movements, 12 cells) (Fig. $5 a$ ). For multipolar cells, the average distance traveled by the soma during translocation was $11.6 \pm 7.7 \mu \mathrm{m}$, and the average duration of movement was $58.3 \pm 36.0 \mathrm{~min}$. Changes of direction in multipolar cells were accomplished by the cell nucleus invading a process whose heading differed from the previous trajectory (mean turn angle, $97.7 \pm 38.9^{\circ}$ ) (Fig. $5 b-d$ ). Before the invasion of a new process, the movement of the cell body would cease (mean rest duration, $53.4 \pm 29.3 \mathrm{~min}$ ), resulting in alternating periods of movement and rest during the course of migration (Fig. $5 g$ ). Multipolar cells 

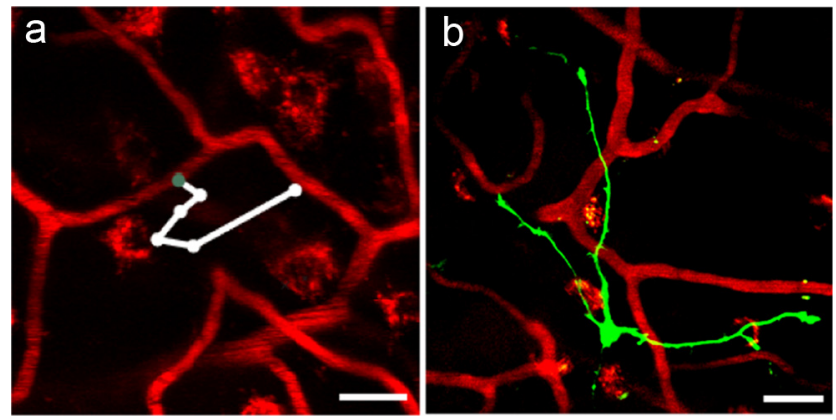

Figure 4. Migratory neurons in HVC do not follow a vascular scaffold. $\boldsymbol{a}$, Horizontal projection of a migration path (white line) of a new neuron in HVC over a $15 \mathrm{~h}$ period superimposed on a maximum projection image of sulforhodamine-labeled vasculature (red). The neuron was imaged at $3 \mathrm{~h}$ intervals by in vivo two-photon microscopy, and the position of the center of the cell body at each time point is indicated by a white circle. The green circle marks the position of the cell body at the first time point. The trajectories of migrating cells did not follow the pattern of the blood vessels ( 0 of 11). $\boldsymbol{b}$, Maximal intensity projection of a GFP-labeled migratory cell (green) and nearby sulforhodamine-labeled blood vessels (red) in HVC. Migrating cells did not make somatic contact with blood vessels. The mean distance from GFP ${ }^{+}$somata to nearest blood vessel across all time points was $8.5 \mu \mathrm{m}$. Scale bars, $25 \mu \mathrm{m}$.

moved up to $37.1 \mu \mathrm{m} / \mathrm{h}(8.5 \pm 6.2 \mu \mathrm{m} / \mathrm{h})$ and changed directions every $152 \pm 54 \mathrm{~min}$ on average. Bipolar cells, as expected, migrated along a straight path away from the lateral ventricle (Fig. $3 e, f)$. We were unable to detect a bias in the headings of multipolar cells ( $p<0.001$, Rayleigh's test; see Materials and Methods). If migrating cells in HVC were following a chemoattractant gradient, one would expect cell headings to be biased toward the source of the chemoreattractant. The multiple migratory directions of multipolar cells within HVC suggests that these cells are not guided by a single point source of diffusible chemical cues.

To compare migration across short- and long-duration imaging sessions, we measured displacement rate for multipolar cells. We observed no significant difference in displacement rate between cells imaged during 6-min-duration time-lapse imaging ( $n=10$ cells) and cells imaged over $3 \mathrm{~h}$ durations $(n=11$ cells; $p=0.8267$, two-tailed $t$ test). To characterize the paths of multipolar cells $(n=24)$ at all time points $(n=641)$, we examined whether displacement rate fitted a linear model, in which displacement scales linearly with time, or a random walk model, in

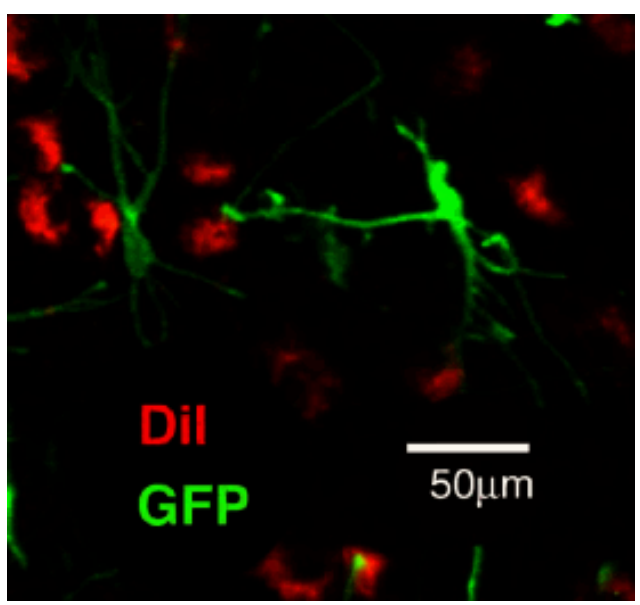

Movie 1. In vivo imaging of neuronal migration in the juvenile zebra finch brain. Time-lapse video of a $\mathrm{GFP}^{+}$multipolar cell (green) in HVC over $5.5 \mathrm{~h}$. The somata of Dil ${ }^{+} \mathrm{HVCX}$ neurons are shown in red. This migrating cell changes directions twice during the $5.5 \mathrm{~h}$ of imaging shown here. Scale bar, $50 \mu \mathrm{m}$. which displacement scales with the square root of time (Gruler and Bültmann, 1984). We found that the migration trajectories of multipolar cells were better fit by a random walk model $\left(r^{2}=0.71\right)$ than by a linear model $\left(r^{2}=0.61\right)(p<0.001$; see Materials and Methods). In contrast to the behavior of multipolar cells, bipolar cells in HVC $(n=2)$ had straight migratory routes consistent with their association with the radial glia scaffold (Fig. 5e,f).

\section{Growth and retraction of processes during migration}

Because the processes of migrating cells served as scaffolds for soma translocation and direction change, we investigated their rearrangement in greater detail (Fig. 6a). Process tips grew and retracted at equal speed $(0.67 \pm 0.64 \mu \mathrm{m} / \mathrm{min})$ (Fig. $6 b)$, but on average, processes that were aligned with the direction of movement (see Materials and Methods) experienced significantly more growth than processes oriented in other directions $(p<$ 0.001 , two-tailed, two-sample $t$ test) (Fig. $6 c$ ). Elongating processes had a swelling at their distal tip (48 of 55 swellings in growing processes) that was absent from retracting processes $(0$ of 55 swellings in retracting processes) (Fig. $6 a$; $p<0.001$, twotailed $z$ test). These swellings resembled axonal growth cones and frequently appeared to make contact with the somata of mature neurons (Fig. $6 d$ and Movie 2), perhaps reflecting a sensory role for these process tips.

\section{Multipolar cells differentiate into neurons after migration ends}

To determine the fate of multipolar cells, we imaged $\mathrm{GFP}^{+}$cells $(n=66)$ at $48 \mathrm{~h}$ intervals beginning at either 4 or $6 \mathrm{dpi}$. Once cells had ceased migrating ( $n=16$ of 66$)$, we were able to monitor their differentiation into mature neurons (Fig. $7 a, b)$. GFP ${ }^{+}$cells labeled on the same day stopped migrating at different times; some cells stopped as early as $10 \mathrm{dpi}$, whereas others continued to migrate even after 18 dpi (Fig. 7c). Based on morphological evidence, including the presence of dendrites and an axon, all 16 postmigratory $\mathrm{GFP}^{+}$cells that we observed in HVC appeared to differentiate into neurons (Fig. 7b) and began to form dendritic spines 4-6 d after they stopped migrating. All of the postmigratory $\mathrm{GFP}^{+}$cells (16 of 16) were found in close proximity to $\mathrm{HVC}_{\mathrm{X}}$ neurons (mean somasoma distance, $2.1 \pm 2.3 \mu \mathrm{m}$ ) (Fig. $7 d, e$ ), and 75\% (12 of 16) were close enough to make soma-soma contact with these cells, although it was not possible to confirm somatic contact given the spatial resolution of our in vivo imaging setup and the nature of DiI labeling in HVC. In contrast, GFP ${ }^{+}$cells that continued migrating over the subsequent imaging interval were significantly farther, on average, from $\mathrm{HVC}_{\mathrm{X}}$ neurons (mean soma to soma distance, $12.2 \pm 8.5 \mu \mathrm{m}$; $p<0.007$, $t$ test; Fig. 7e).

\section{Discussion}

A wandering form of migration in the postnatal forebrain Using histological analysis and in vivo two-photon imaging, we have characterized the migration of new neurons in the juvenile zebra finch forebrain. We focused our attention on the song nucleus HVC because it has been hypothesized that neurogenesis in this region is involved in song learning and because its superficial position allowed migration to be imaged in vivo. Examination of histological sections from HVC 1 week after infection with oncoretroviral vectors carrying the gene for GFP revealed that some young neurons $(\sim 30 \%)$ had a bipolar morphology and were tightly apposed to the fibers of radial glia. This morphology is consistent with those of immature neurons undergoing radial migration, which is thought to be the primary mode of migration for projection neurons during the assembly of the mammalian 

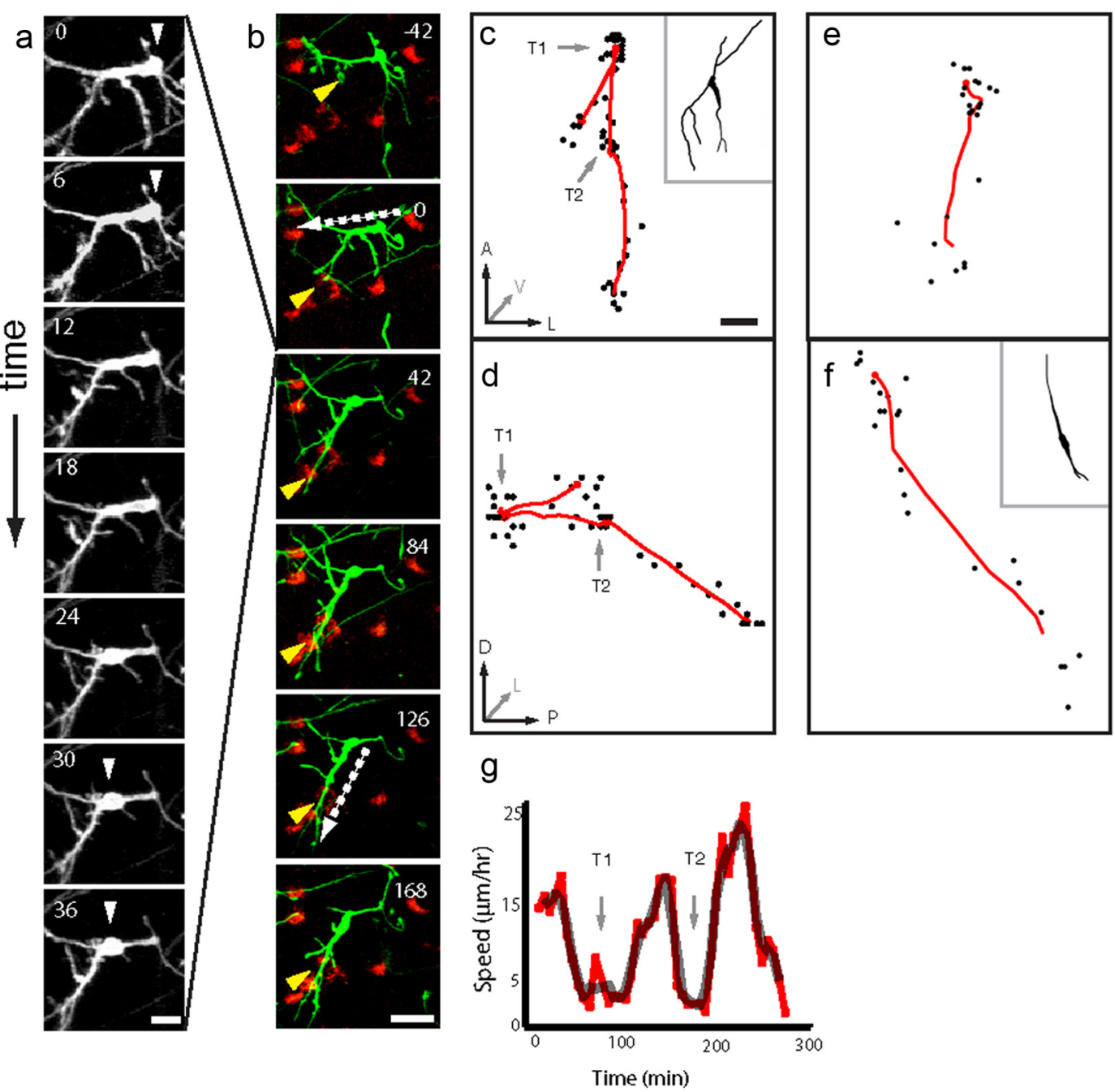

Figure 5. Multipolar cells move forward by soma translocation and change direction by soma invasion. $\boldsymbol{a}, \boldsymbol{b}$, Time-lapse series of migration in vivo for a single multipolar cell. Each image shows a maximal intensity projection of a GFP ${ }^{+}$cell in HVC. $\boldsymbol{a}$, Forward motion was accomplished by soma translocation along an existing process. Time, in minutes, is indicated in the top left corner of each panel. Arrowheads at $t=0,6,30$, and 36 min identify the soma during the stationary phase. Scale bar, $10 \mu \mathrm{m}$. $\boldsymbol{b}$, Direction change (at $t=126 \mathrm{~min}$ ) was accomplished by the movement of the cell body into a newly extended process. Dashed arrows at $t=0$ and 126 min indicate the upcoming direction of movement. Arrowhead at $t=-42$ min indicates the formation of the new leading process. GFP ${ }^{+}$multipolar cell is shown in green, and surrounding Dil ${ }^{+} \mathrm{HVC}_{x}$ cells are labeled in red. Scale bar, $20 \mu \mathrm{m}$. $\boldsymbol{c}, \boldsymbol{d}$, Reconstruction of a 300-min migratory trajectory from a multipolar cell. Trajectory for the same cell is shown in the horizontal plane (c) and the sagittal plane (d) (A, anterior; P, posterior; D, dorsal; $\mathrm{V}$, ventral; L, lateral). Black dots represent the location of the soma center at $6 \mathrm{~min}$ intervals, and the red line represents the smoothed trajectory (36 min sliding average). Scale bar, $5 \mu \mathrm{m}$. Gray arrows, labeled T1 and T2, indicate turns in the migration trajectory. The morphology of the multipolar cell in the horizontal plane is shown in the top right corner of c.e, $f$, Reconstruction of a 150 min migratory trajectory from a bipolar cell. The morphology of the bipolar cell in the sagittal plane is shown in the top right corner of $\boldsymbol{f} . \boldsymbol{g}$, Plot of soma speed versus time for the trajectory shown in c and $\boldsymbol{d}$. Raw data (red line) and three-point sliding average (gray line) show speed calculated from smoothed trajectory in $\boldsymbol{c}$ and $\boldsymbol{d}$. Turns T1 and T2 (gray arrows) occur during stationary phase.

cortex as well as the songbird forebrain. However, the majority of young migratory neurons $(\sim 70 \%)$ exhibited a multipolar morphology, with no obvious polarity, and multiple processes emanating from the soma. In vivo imaging revealed that the processes from these cells were dynamic, growing and retracting in multiple directions. Surprisingly, in vivo imaging also revealed that these young multipolar neurons did not migrate along straight paths. Instead, they moved in a saltatory pattern, alternating between periods of forward movement and periods of rest, during which the direction of movement of the cell changed. This migratory behavior, which we term wandering migration, contrasts with the common view that neurons, derived from the pallial VZ, migrate in straight lines along a radial glia scaffold.

A similar form of wandering migration has been observed for interneurons migrating in in vitro slice explants from the embryonic mammalian cortex. Migratory interneurons, derived from the medial and lateral ganglionic eminences, can exhibit multipolar morphology (Nadarajah et al., 2003; Tanaka et al., 2006) and exhibit dynamic branch growth, leading to the formation of new leading processes (Britto et al., 2009; Martini et al., 2009). Time-lapse imaging in vitro has revealed that young cortical interneurons, migrating in the intermediate zone and marginal zone, also move in an undirected, random walk pattern (Tabata and Nakajima, 2003; Tanaka et al., 2009). It has been suggested that this random walk form of migration may be an artifact of the in vitro slice preparation used in time-lapse experiments (Tanaka et al., 2009). However, our two-photon imaging results indicate that this wandering behavior also occurs in vivo and may be used for the displacement of neurons derived from the pallial VZ.

Although young cortical projection neurons in mammals do not exhibit wandering migration, these cells transiently become multipolar after entering the intermediate zone during radial mi- 
a

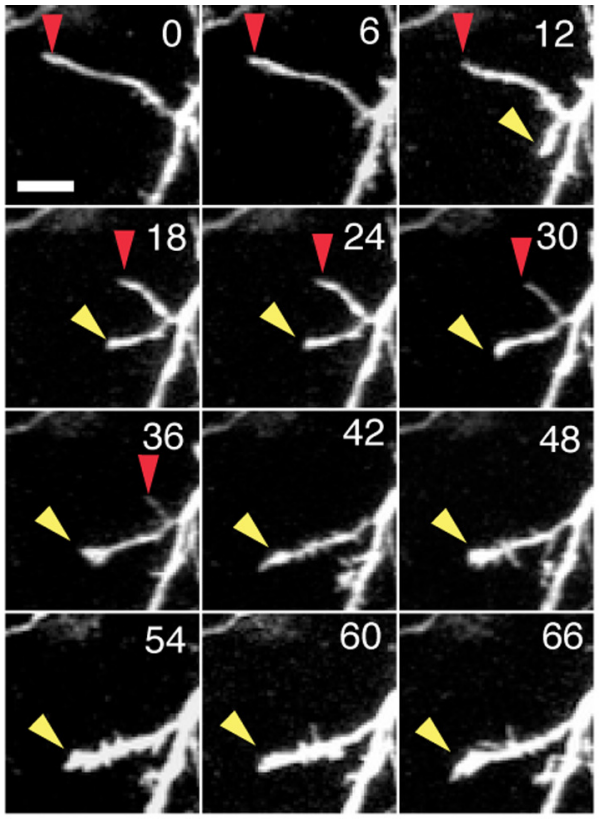

b

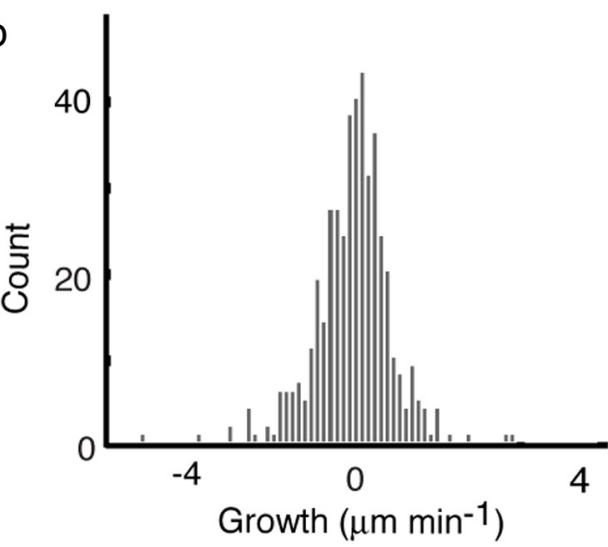

C

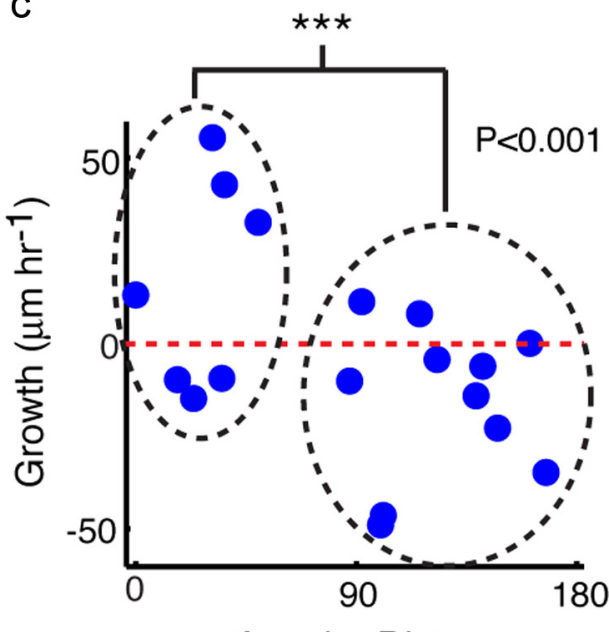

Angular Distance

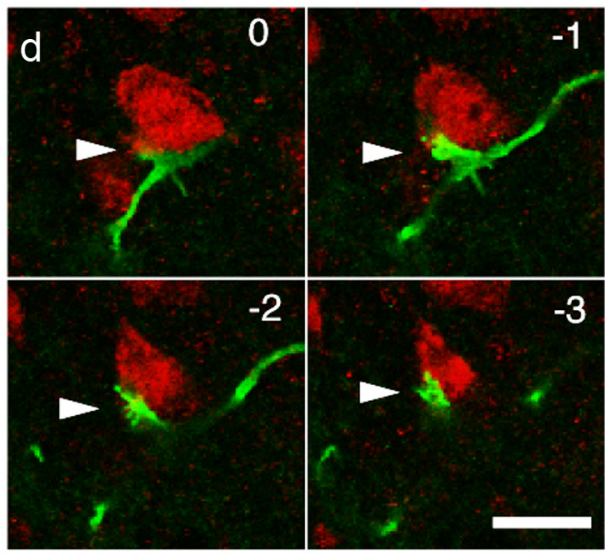

Figure 6. Processes of multipolar cells are highly dynamic, grow in multiple directions, and make contact with mature neurons. $\boldsymbol{a}$, Imaging time series of a retracting process (red arrowhead at tip) and a growing process (yellow arrowhead at tip). Time in minutes is indicated in the top right of each panel. Scale bar, $10 \mu \mathrm{m}$. $\boldsymbol{b}$, Histogram of the length change rate for all the processes of four multipolar cells. Mean growth rate for all processes was not significantly different from 0 ( $t$ test, $p=0.625$ ), suggesting that multipolar cells did not increase in size as they migrated but merely changed shape. $c, 0 \mathrm{n}$ average, processes (blue circles) within $60^{\circ}$ of the direction of soma movement grew during the hour before movement of the cell body, whereas processes oriented away from the direction of movement $>60^{\circ}$ retracted. Red dotted line corresponds to $0 \mu \mathrm{m}$ growth per hour. $\boldsymbol{d}$, Single optical confocal sections of a GFP ${ }^{+}$process tip (green) making contact (arrowhead) with a NeuN $^{+}$soma (red) in HVC. Each section is separated by a $1 \mu \mathrm{m}$ step; relative depth in micrometers is indicated on the top right of each panel. Scale bar, $10 \mu \mathrm{m}$.

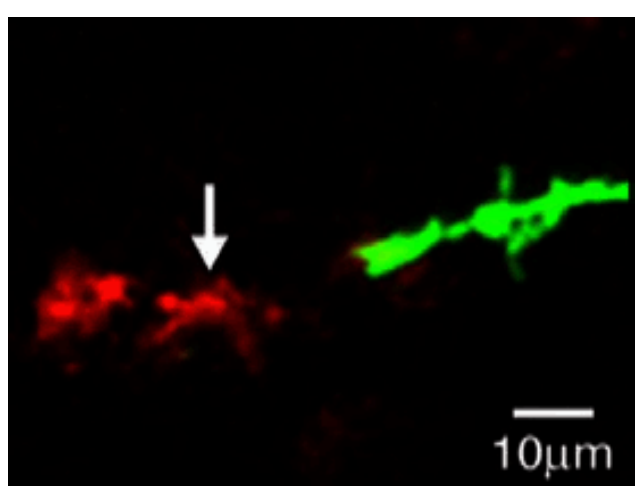

Movie 2. In vivo time-lapse movie of a process tip of a GFP ${ }^{+}$multipolar cell (green) that makes contact with the somata of a Dil ${ }^{+}$HVCX neuron (red). Arrow indicates the HVCX neuron that is the target of the extending GFP ${ }^{+}$process. Note the characteristic swelling of the tip of the process during extension. Total elapsed time is $7 \mathrm{~h}$. Scale bar, $10 \mu \mathrm{m} . "$ gration (LoTurco and Bai, 2006). During this multipolar stage, cells detach from radial glia and their processes move in a dynamic manner (Tabata and Nakajima, 2003; Noctor et al., 2004). However, during this stage, movement of the cell soma is minimal (Noctor et al., 2004). In contrast to the short time during which cortical projection neurons become multipolar, neurons in the songbird pallium exhibit multipolar morphology for many days, over which period they travel hundreds of micrometers.

\section{Bipolar and multipolar neurons in HVC}

Our experiments revealed the presence of both multipolar and bipolar migrating cells in the juvenile avian forebrain. As in mammalian cortical migration, the bipolar and multipolar morphologies may also represent two distinct phases of migration, between which young neurons can switch (Nadarajah et al., 2003). Indeed, it was proposed previously that neurons in the canary brain migrated along radial glia for the first few weeks on their way to deep brain regions and then transitioned to a second form of migration independent of radial glia (Alvarez-Buylla and 

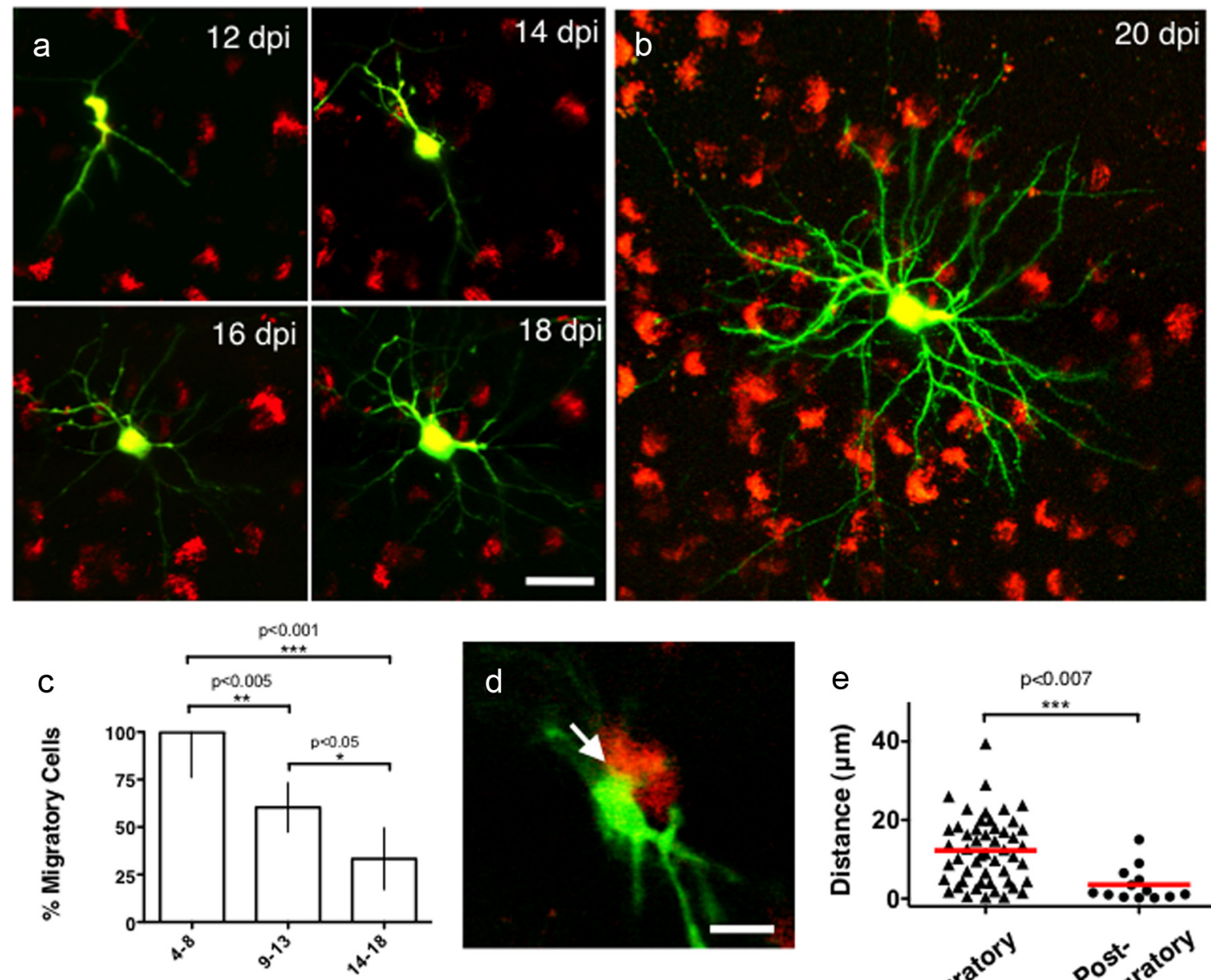

dpi e

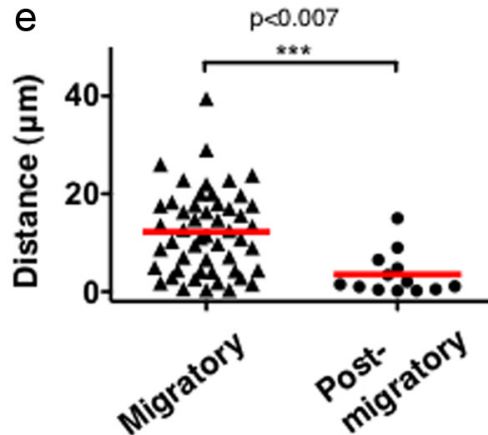

Figure 7. Multipolar cells stop migrating and differentiate into neurons in close proximity to mature $\mathrm{HVC}_{\mathrm{x}}$ neurons. $\boldsymbol{a}, \boldsymbol{b}$, Time series showing the differentiation of a multipolar GFP + cell (green) in HVC. Somata of Dil ${ }^{+} \mathrm{HVC}_{\mathrm{x}}$ are shown in red. Days after injection are indicated in the top right corner of each panel. At $12 \mathrm{dpi}$, the GFP ${ }^{+}$cell is still migratory. By 14 dpi, it stopped migrating and began to differentiate into a neuron. $\boldsymbol{b}$, By $20 \mathrm{dpi}$, the GFP ${ }^{+}$cell has adopted the morphology of a mature neuron. Scale bar, $20 \mu \mathrm{m}$. $\boldsymbol{c}$, Change in the ratio of migrating GFP ${ }^{+}$cells to total GFP ${ }^{+}$cells within HVC determined by in vivo imaging at different time points after injection. $\boldsymbol{d}$, Single optical section of a multipolar cell (green) in HVC at $10 \mathrm{dpi}$, soon after it stopped migrating. Arrow indicates the point of contact between the cell bodies of the GFP ${ }^{+}$cell (green) and a mature HVC $($red). $e$, Distance from the somata of $\mathrm{GFP}^{+}$cells in HVC to the soma of the nearest $\mathrm{HVC}_{x}$ neuron is plotted. On average, postmigratory $\mathrm{GFP}^{+}{ }^{+}$neurons (circles) were significantly closer than migratory GFP ${ }^{+}{ }_{\text {neurons }}$ (triangles) to $\mathrm{HVC}_{\mathrm{X}}$ neurons $(p<0.007)$. Red lines represent the means.

Nottebohm, 1988). Although we did not observe these hypothetical transitions between radial to wandering migrations during in vivo time-lapse imaging, our data are consistent with this model in which young neurons initially migrate along a radial glia scaffold and then switch to wandering migration for the final few hundred micrometers. Several observations suggest that this hypothetical transition between radial to wandering migration would be difficult to detect with our imaging system. First, based on our histological analysis at $8 \mathrm{dpi}$, cells with a bipolar morphology constitute only $\sim 30 \%$ of young neurons in HVC. Second, radially migrating cells are difficult to detect in vivo because of their simple morphology and the fact that their main axis is oriented perpendicular to our imaging field of view. Finally, given their speed and migration trajectory, we were seldom able to track individual cells that were migrating radially. Our imaging region was restricted to the dorsal $\sim 300 \mu \mathrm{m}$ of the brain and radially migrating cells descend ventrally, following the scaffold of radial fibers. Therefore, most bipolar cells would quickly move out of imaging field into regions in which we could not track them. Given these facts, one would expect the detection of the hypothetical transition between radial and non-radial migration in vivo to be rare. Therefore, the fact that we did not observe a transition from bipolar to multipolar does not rule out this twostage model of neuron migration.

Alternatively, the bipolar and multipolar cells that we observed may represent different populations of neurons that exclusively use radial or wandering forms of migration, respectively, for their displacements. Albeit possible, we think that this scenario is not likely given that the evidence from other systems indicates that most neuronal types studied do not use a single form of migration exclusively. For example, during the course of their journey, neurons in the mammalian cortex (O'Rourke et al., 1992; Nadarajah et al., 2003; Noctor et al., 2004), cerebellum (Köster and Fraser, 2001), and olfactory bulb (Lois et al., 1996; Hu et al., 1996) have been observed to exhibit changes in morphology, polarity, direction, and the migratory scaffold they use. However, it is possible that some of the bipolar cells that we observed may belong to two different populations. First, bipolar cells migrating radially in their initial stages of migration that would transition to wandering migration and integrate within $\mathrm{HVC}$ and become $\mathrm{HVC}_{\mathrm{RA}}$ neurons. Second, bipolar cells migrating radially through $\mathrm{HVC}$ whose final destination 
would be outside of HVC. Additional experiments will be necessary to clarify these issues.

\section{Wandering migration and the formation of neuronal clusters}

Although new neurons in HVC migrate in a wandering manner, their integration appears to follow a pattern, because these new cells preferentially integrate into positions in which their soma comes into close proximity to the somata of mature resident $\mathrm{HVC}_{\mathrm{X}}$ neurons. A similar phenomenon has been documented in the HVC of adult canaries in which new neurons integrate into positions in which they make close soma-soma contact with mature $\mathrm{HVC}_{\mathrm{X}}, \mathrm{HVC}_{\mathrm{RA}}$, and interneurons (Kirn et al., 1999). Indeed, analysis of HVC by electron microscopy has revealed that the somata of new HVC neurons establish membrane-membrane contacts with mature HVC neurons (Burd and Nottebohm, 1985). Moreover, newly integrated cells often contact multiple mature neurons simultaneously, thereby forming small groups of neurons, which have been referred to as "clusters" (Burd and Nottebohm, 1985; Holzenberger et al., 1997; Kirn et al., 1999). Such cluster organization is evident in the HVC adult zebra finches as well (B. B. Scott, unpublished results).

It has been speculated that these clusters may represent an important anatomical unit in the songbird HVC. Interestingly, ultrastructural analysis suggests that neurons within these clusters may be coupled by gap junctions (Gahr and Garcia-Segura, 1996). This observation has led to the hypothesis that young $\mathrm{HVC}_{\mathrm{RA}}$ neurons and mature $\mathrm{HVC}_{\mathrm{X}}$ neurons may be electrically coupled and that such clustering could facilitate the entrainment of new cells into the functioning circuit (Alvarez-Buylla and Kirn, 1997). Additional experiments are required to elucidate the potential relationship between migrating neurons and mature neurons in HVC. However, the fact that wandering neurons terminate their migration adjacent to $\mathrm{HVC}_{\mathrm{X}}$ during the juvenile period may account for the existence of neuronal clusters in HVC in the adult songbird brain and suggests that the termination of the wandering migration of a young neuron may be regulated by interactions with mature neurons.

The mature brain presents migrating neurons with different challenges compared with the embryonic brain. As development proceeds, the stability of neuronal connections increases (Holtmaat et al., 2005) and the amount of extracellular space decreases (Bondareff and Narotzky, 1972). One cellular strategy to navigate the landscape of mature neural circuits is to move through established corridors in the neuropil. This is the approach used by young olfactory bulb granule neurons gliding along the rostral migratory stream (Lois et al., 1996). However, for young neurons to disperse in three dimensions and to migrate among the mature resident neurons, another strategy may be required. The wandering behavior of migratory cells in HVC may be a strategy that allows new neurons to navigate the complex terrain of the mature nervous system. Our observations are also consistent with a model of circuit assembly in which young neurons are not committed to a particular integration target; instead, they may patrol the forebrain until signals from preexisting neurons prompt them to terminate their migration and integrate into the circuit.

\section{References}

Altman J (1969) Autoradiographic and histological studies of postnatal neurogenesis. IV. Cell proliferation and migration in the anterior forebrain, with special reference to persisting neurogenesis in the olfactory bulb. J Comp Neurol 137:433-457.

Altman J, Das GD (1965) Autoradiographic and histological evidence of postnatal hippocampal neurogenesis in rats. J Comp Neurol 124:319-335

Alvarez-Borda B, Nottebohm F (2002) Gonads and singing play separate, additive roles in new neuron recruitment in adult canary brain. J Neurosci 22:8684-8690.

Alvarez-Buylla A, Kirn JR (1997) Birth, migration, incorporation, and death of vocal control neurons in adult songbirds. J Neurobiol 33:585-601.

Alvarez-Buylla A, Nottebohm F (1988) Migration of young neurons in adult avian brain. Nature 335:353-354.

Alvarez-Buylla A, Theelen M, Nottebohm F (1988a) Birth of projection neurons in the higher vocal center of the canary forebrain before, during, and after song learning. Proc Natl Acad Sci USA 85:8722-8726.

Alvarez-Buylla A, Theelen M, Nottebohm F (1988b) Mapping of radial glia and of a new cell type in adult canary brain. J Neurosci 8:2707-2712.

Alvarez-Buylla A, Kirn JR, Nottebohm F (1990a) Birth of projection neurons in adult avian brain may be related to perceptual or motor learning. Science 249:1444-1446.

Alvarez-Buylla A, Theelen M, Nottebohm F (1990b) Proliferation "hot spots" in adult avian ventricular zone reveal radial cell division. Neuron 5:101-109.

Ayala R, Shu T, Tsai LH (2007) Trekking across the brain: the journey of neuronal migration. Cell 128:29-43.

Barami K, Iversen K, Furneaux H, Goldman SA (1995) Hu protein as an early marker of neuronal phenotypic differentiation by subependymal zone cells of the adult songbird forebrain. J Neurobiol 28:82-101.

Bondareff W, Narotzky R (1972) Age changes in the neuronal microenvironment. Science 176:1135-1136.

Boseret G, Ball GF, Balthazart J (2007) The microtubule-associated protein doublecortin is broadly expressed in the telencephalon of adult canaries. J Chem Neuroanat 33:140-154.

Bovetti S, Hsieh YC, Bovolin P, Perroteau I, Kazunori T, Puche AC (2007) Blood vessels form a scaffold for neuroblast migration in the adult olfactory bulb. J Neurosci 27:5976-5980.

Britto JM, Johnston LA, Tan SS (2009) The stochastic search dynamics of interneuron migration. Biophys J 97:699-709.

Burd GD, Nottebohm F (1985) Ultrastructural characterization of synaptic terminals formed on newly generated neurons in a song control nucleus of the adult canary forebrain. J Comp Neurol 240:143-152.

Fisher NI (1996) Statistical analysis of circular data. Cambridge, UK: Cambridge UP.

Francis F, Koulakoff A, Boucher D, Chafey P, Schaar B, Vinet MC, Friocourt G, McDonnell N, Reiner O, Kahn A, McConnell SK, Berwald-Netter Y, Denoulet P, Chelly J (1999) Doublecortin is a developmentally regulated, microtubule-associated protein expressed in migrating and differentiating neurons. Neuron 23:247-256.

Gahr M, Garcia-Segura LM (1996) Testosterone-dependent increase of gap-junctions in HVC neurons of adult female canaries. Brain Res 712:69-73.

Gleeson JG, Lin PT, Flanagan LA, Walsh CA (1999) Doublecortin is a microtubule-associated protein and is expressed widely by migrating neurons. Neuron 23:257-271.

Gruler H, Bültmann BD (1984) Analysis of cell movement. Blood cells 10:61-77.

Holtmaat AJ, Trachtenberg JT, Wilbrecht L, Shepherd GM, Zhang X, Knott GW, Svoboda K (2005) Transient and persistent dendritic spines in the neocortex in vivo. Neuron 45:279-291.

Holzenberger M, Jarvis ED, Chong C, Grossman M, Nottebohm F, Scharff C (1997) Selective expression of insulin-like growth factor II in the songbird brain. J Neurosci 17:6974-6987.

Hu H, Tomasiewicz H, Magnuson T, Rutishauser U (1996) The role of polysialic acid in migration of olfactory bulb interneuron precursors in the subventricular zone. Neuron 16:735-743.

Kaslin J, Ganz J, Brand M (2008) Proliferation, neurogenesis and regeneration in the non-mammalian vertebrate brain. Philos Trans R Soc Lond B Biol Sci 363:101-122.

Kirn J, O'Loughlin B, Kasparian S, Nottebohm F (1994) Cell death and neuronal recruitment in the high vocal center of adult male canaries are temporally related to changes in song. Proc Natl Acad Sci USA 91:7844-7848.

Kirn JR, Fishman Y, Sasportas K, Alvarez-Buylla A, Nottebohm F (1999) Fate of new neurons in adult canary high vocal center during the first 30 days after their formation. J Comp Neurol 411:487-494. 
Köster RW, Fraser SE (2001) Direct imaging of in vivo neuronal migration in the developing cerebellum. Curr Biol 11:1858-1863.

Lois C, Alvarez-Buylla A (1994) Long-distance neuronal migration in the adult mammalian brain. Science 264:1145-1148.

Lois C, García-Verdugo JM, Alvarez-Buylla A (1996) Chain migration of neuronal precursors. Science 271:978-981.

Lois C, Hong EJ, Pease S, Brown EJ, Baltimore D (2002) Germline transmission and tissue-specific expression of transgenes delivered by lentiviral vectors. Science 295:868-872.

LoTurco JJ, Bai J (2006) The multipolar stage and disruptions in neuronal migration. Trends Neurosci 29:407-413.

Luo M, Ding L, Perkel DJ (2001) An avian basal ganglia pathway essential for vocal learning forms a closed topographic loop. J Neurosci 21:6836-6845.

Martini FJ, Valiente M, López Bendito G, Szab ó G, Moya F, Valdeolmillos M, Marín O (2009) Biased selection of leading process branches mediates chemotaxis during tangential neuronal migration. Development 136:41-50.

Mullen RJ, Buck CR, Smith AM (1992) NeuN, a neuronal specific nuclear protein in vertebrates. Development 116:201-211.

Nadarajah B, Alifragis P, Wong RO, Parnavelas JG (2003) Neuronal migration in the developing cerebral cortex: observations based on real-time imaging. Cereb Cortex 13:607-611.

Noctor SC, Martínez-Cerdeño V, Ivic L, Kriegstein AR (2004) Cortical neurons arise in symmetric and asymmetric division zones and migrate through specific phases. Nat Neurosci 7:136-144.

Nordeen KW, Nordeen EJ (1988) Projection neurons within a vocal motor pathway are born during song learning in zebra finches. Nature 334:149-151.

Nottebohm F (1985) Neuronal replacement in adulthood. Ann N Y Acad Sci 457:143-161.

Okano H, Sawamoto K (2008) Neural stem cells: involvement in adult neu- rogenesis and CNS repair. Philos Trans R Soc Lond B Biol Sci 363:2111-2122.

O'Rourke NA, Dailey ME, Smith SJ, McConnell SK (1992) Diverse migratory pathways in the developing cerebral cortex. Science 258:299-302.

Paton JA, Nottebohm FN (1984) Neurons generated in the adult brain are recruited into functional circuits. Science 225:1046-1048.

Pologruto TA, Sabatini BL, Svoboda K (2003) ScanImage: flexible software for operating laser scanning microscopes. Biomed Eng Online 2:13.

Rakic P (1972) Mode of cell migration to the superficial layers of fetal monkey neocortex. J Comp Neurol 145:61-83.

Roe T, Reynolds TC, Yu G, Brown PO (1993) Integration of murine leukemia virus DNA depends on mitosis. EMBO J 12:2099-2108.

Scharff C, Kirn JR, Grossman M, Macklis JD, Nottebohm F (2000) Targeted neuronal death affects neuronal replacement and vocal behavior in adult songbirds. Neuron 25:481-492.

Scott BB, Lois C (2007) Developmental origin and identity of song system neurons born during vocal learning in songbirds. J Comp Neurol 502:202-214.

Tabata H, Nakajima K (2003) Multipolar migration: the third mode of radial neuronal migration in the developing cerebral cortex. J Neurosci 23:9996-10001.

Tanaka DH, Maekawa K, Yanagawa Y, Obata K, Murakami F (2006) Multidirectional and multizonal tangential migration of GABAergic interneurons in the developing cerebral cortex. Development 133: 2167-2176.

Tanaka DH, Yanagida M, Zhu Y, Mikami S, Nagasawa T, Miyazaki J, Yanagawa Y, Obata K, Murakami F (2009) Random walk behavior of migrating cortical interneurons in the marginal zone: time-lapse analysis in flat-mount cortex. J Neurosci 29:1300-1311.

van Praag H, Schinder AF, Christie BR, Toni N, Palmer TD, Gage FH (2002) Functional neurogenesis in the adult hippocampus. Nature 415:1030 1034. 